\title{
DESDOBRAMENTOS PSICOPATOLÓGICOS DA IDENTIFICAÇÃO PROJETIVA NA PARTE BEBÊ DO SELF
}

\section{DANIEl PINho SEnos de JeSUS $\mathbb{D}$; Silvia Maria Abu-Jamra Zornig $\mathbb{D}$}

\section{Daniel Pinho Senos de Jesus ${ }^{1}$}

Doutorando em Psicologia Clínica pelo Programa de Pós-Graduação em Psicologia Clínica da Pontifícia Universidade Católica do Rio de Janeiro. Professor da Pós-Graduação em Psicologia Clínica com Crianças da Pontifícia Universidade Católica do Rio de Janeiro.

\section{Silvia Maria Abu-Jamra Zornig ${ }^{1}$}

Doutora em Psicologia Clínica pelo Programa de Pós-Graduação em Psicologia Clínica da Pontifícia Universidade Católica do Rio de Janeiro. Professora do Programa de Pós-Graduação em Psicologia Clínica e do Departamento de Psicologia da Pontifícia Universidade Católica do Rio de Janeiro.

${ }^{1}$ Pontifícia Universidade Católica do Rio de Janeiro, Rio de Janeiro-RJ, Brasil.
RESUMO: Discutiremos os desdobramentos psicopatológicos na zona arcaica da subjetividade quando a identificação projetiva perde sua dimensão de comunicação primitiva, assumindo um caráter radical de evacuação e prejudicando a rêverie materna. Estudaremos as experiências precoces do psiquismo englobadas na parte bebê do self, fundamentais aos processos de simbolização primária. Suas falhas se manifestam na clínica através de intensos sofrimentos capitaneados por angústias primitivas, como as de abandono e de separação, que acarretam respostas radicais, tais como a fragmentação e a despersonalização. Apresentaremos um fragmento clínico para ilustrar a forma de desorganização psíquica própria às falhas na parte bebê do self.

Palavras-chave: identificação projetiva; constituição psíquica; terror sem nome; simbolização primária; rêverie materna

Abstract: Psychopathological evolution of projective identification in the baby part of the self. We will discuss the psychopathological evolution in the archaic zone of subjectivity when the projective identification loses its primitive communication dimension, assuming a radical role of evacuation and damaging the maternal rêverie. We will study the early experiences of the psyche embedded in the baby part of the self, fundamental to the processes of primary symbolization. Their failures are manifested in the clinic through intense sufferings captained by primitive anxieties, such as abandonment and separation, which lead to severe responses such as fragmentation and depersonalization. We will present a clinical fragment to illustrate the archaic forms of psychic disorganization proper to failures in the baby part of the self.

Keywords: projective identification; psychic constitution; nameless dread; primary symbolization; maternal rêverie

DOI - http://dx.doi.org/10.1590/1809-44142021003005

Todo o conteúdo deste periódico, exceto onde estiver identificado, está licenciado sob uma licença Creative Commons (cc by 4.0 ) 


\section{INTRODUÇÃO}

No presente trabalho, discutiremos alguns aspectos relativos às falhas precoces na relação com o objeto primordial, no intuito de compreender as configurações psicopatológicas que desafiam o cotidiano do trabalho psicanalítico, em função da carência dos processos simbólicos. Tais falhas, ao incidirem em momentos basais da constituição subjetiva, desencadeiam defesas extremas em relação ao outro, uma vez que os processos iniciais de integração foram abalados. Dessa forma, abordaremos alguns fatores que fundamentam a nossa investigação a respeito das problemáticas relacionadas às perturbações da zona arcaica da subjetividade, assim como a importância da qualidade da relação objetal para a constituição psíquica.

Primeiramente, discorreremos a respeito da relação primordial mãe-bebê a partir dos conceitos de identificação projetiva e rêverie materna, com o objetivo de ressaltar a relevância dessa primeira relação intersubjetiva para a constituição psíquica. A identificação projetiva, compreendida como forma rudimentar de comunicação, é a forma básica através da qual o bebê despeja uma série de material bruto, indigesto, no continente materno, com a expectativa de que ela o abarque e devolva de forma metabolizada. No entanto, quando a rêverie materna falha em sua função de acolhimento, a identificação projetiva perde gradualmente sua dimensão de comunicação, tornando-se uma defesa patológica através da qual o bebê despeja seus elementos brutos para fora de si, como uma estratégia desesperada de sobrevivência. Nosso interesse é entender quais são as implicações da falha da rêverie materna e a utilização da identificação projetiva como forma de pura descarga para a subjetividade, em especial para a dimensão mais precoce dela, que envolvem os primeiros processos de simbolização.

Posteriormente, conceituaremos a zona arcaica da subjetividade, compreendida por Albert Ciccone (2012; 2013) como a parte bebê do self. Destacaremos também, a partir de Frances Tustin $(1980 ; 1984)$, de que forma as sensações primitivas moldam as primeiras relações do bebê com o mundo e compõem a dinâmica de integração nos primórdios da vida psíquica. Tal dimensão sensorial funciona como uma matriz primordial do psiquismo, através da qual sensações corporais - sentidas como mole e duro - estruturam os processos de integração e de relação com o objeto primordial. As relações do bebê com o ambiente, assim como o singular estado de preocupação do casal parental, serão levados em consideração, considerando que a dinâmica intersubjetiva possui um papel fundamental para a estruturação da subjetividade.

Por fim, ilustraremos a nossa argumentação com um fragmento clínico.

\section{ACOLHIMENTO E COMUNICAÇÃO NOS PRIMÓRDIOS DA VIDA PSÍQUICA}

Apresentaremos a seguir alguns aspectos concernentes à identificação projetiva e sua importância para a constituição subjetiva, uma vez que esse processo se refere à forma mais primitiva de comunicação entre a mãe e seu bebê. Essa interação arcaica é composta pelo processo de rêverie materna, através do qual a mãe acolhe uma série de elementos brutos que o bebê não consegue metabolizar por conta própria e os devolve para ele de forma passível de ser assimilada-sonhada (OGDEN, 2005). Dessa forma, a identificação projetiva é a forma básica de comunicação não só da mãe e seu bebê, mas das relações interpessoais de forma geral, quando o processo de rêverie é devidamente internalizado e passa a constituir a função alfa ${ }^{1}$ (BION, 1962/1991). Nosso interesse é buscar maior compreensão a respeito das falhas que incidem nesse complexa interação mãe-bebê quando a rêverie materna não é capaz de digerir os elementos beta do bebê, devolvendo-os como elementos bizarros, impossíveis de serem assimilados (BION, 1962/1991; CHUSTER, 1999; OGDEN, 2005). Nesse sentido, a identificação projetiva perde sua vertente comunicacional e assume um caráter patológico, prevalecendo como puro veículo de evacuação frente à iminência de destruição do aparelho psíquico e de sua capacidade de fazer vínculos.

O conceito de identificação projetiva foi cunhado por Melanie Klein em 1946, em seu trabalho dedicado aos mecanismos esquizoides (KLEIN, 1946/2006). Nesse seminal texto, a autora formaliza a identificação projetiva como uma das defesas próprias da posição esquizoparanoide, ativada contra a angústia paranoide, em conjunto com a cisão, a negação e a idealização.

Donald Meltzer (2008/2017) afirma que o referido texto de Klein a respeito dos mecanismos esquizoides denota uma importante distinção do modelo freudiano de pensamento, que já vinha sendo delineada pela autora em suas contribuições sobre a concretude da realidade psíquica, os objetos internalizados e o papel das fantasias inconscientes na implementação das defesas do psiquismo. "Essa fase foi inaugurada pela descrição dos processos de clivagem, em que partes do self não somente incorporam aspectos do id, mas também as-

\footnotetext{
${ }^{1}$ Bion (1961/1991; 1962/1991) descreve a função alfa como a responsável por metabolizar os elementos brutos no psiquismo, nomeados como beta pelo autor, e transformá-los em material passível de ser sonhado, denominado elemento alfa.
} 
pectos do objeto interno" (MELTZER, 2008/2017, p. 13).

Conforme constata Meltzer (2008/2017), nessa obra, Klein busca descrever os mecanismos da posição esquizoparanoide, no intuito de descrever os pontos de fixação próprios às patologias, tais como a esquizofrenia, a paranoia e os estados maníaco-depressivos. Os impulsos sádico-orais do bebê em relação à mãe visam depositar seus próprios excrementos dentro dela, em uma tentativa de penetrar no corpo materno e controlá-lo, o que caracterizaria os movimentos fantasmáticos da identificação projetiva. James Grotstein (2007/2010, p. 179) complementa ao destacar que a identificação projetiva comporta uma importante conexão entre impulsos sádico-orais e anais para lidar com a angústia paranoide, assim como a personificação dos aspectos cindidos do self na vida fantasmática do sujeito. Outro fato importante para a compreensão da identificação projetiva tal qual proposta por Klein nesse período é a dinâmica da cisão, compreendida em primeira instância como um processo passivo; o ego teria uma tendência a se despedaçar frente à pressão exercida por uma ameaça. Posteriormente, a clivagem seria compreendida como um processo ativo e que, tanto o self como os objetos internos e externos, operam com a cisão de forma ativa e simultânea (MELTZER, 2008/2017, p. 14-15).

Para Jean-Michel Petot (1982/2016, p. 123), o conceito de identificação projetiva ocupou um lugar importante no sistema kleiniano, uma vez que inaugura uma compreensão a respeito da identificação, de caráter projetivo, no estágio esquizoide, assim como redefine a relação existente entre a posição paranoide e a depressiva. É importante salientar que, na obra da autora, não havia lugar para a identificação propriamente dita na etapa de prevalência dos objetos parciais até a proposição a respeito da identificação projetiva.

É notável que a autora enfatize a radicalidade dessa modalidade de identificação ao associá-la aos impulsos agressivos que envolvem, de forma concomitante, os movimentos de projeção e introjeção, descritos pela autora como os atos de expulsão de substâncias perigosas para dentro do corpo materno, no primeiro; e o morder e sugar até exaurir, para o segundo movimento (KLEIN, 1946/2006, p. 27). Há uma complexificação da relação entre introjeção e projeção, anteriormente compreendida no sistema kleiniano de forma tendenciosa como a primeira sendo "boa" e a segunda "má". Os movimentos sádicos em relação ao corpo da mãe são passíveis de serem introjetivos - como o sugar, esvaziar e morder - e projetivos - como a expulsão de substâncias perigosas e a penetração (PETOT, 1982/2016, p. 123-124). Conforme destacam Cintra e Ribeiro (2018, p. 120), a identificação projetiva é uma forma particular de identificação que implica na expulsão de partes do self dentro do objeto, o que leva a uma confusão entre sujeito e objeto e enfraquece o ego.

A identificação projetiva também teria como objetivo a tentativa de conservar tanto os elementos projetados como também o próprio objeto, em uma concepção próxima à pulsão de dominação descrita por Freud (1905/2011). Nesse sentido, a fantasia descrita seria a de controlar de forma onipotente uma parte do self que seria projetada no interior do objeto materno, com o qual o bebê vivenciaria um estado confusional; a mãe, por portar tais elementos do self é experimentada como não-diferenciada do mesmo (PETOT, 1982/2016, p. 124).

Também é importante salientar a importância atribuída à identificação projetiva em relação às partes boas do self como fornecedora das condições necessárias para o estabelecimento de relações objetais de amor, assim como para os processos de integração do ego. Para Petot (1982/2016 p. 125), a identificação projetiva "boa" permite o entendimento de que há uma interação recíproca entre o bebê e a mãe, na qual aquele pode introjetar o bom objeto na medida em que projeta partes boas suas no objeto materno. Esta interação determina a qualidade da relação objetal estabelecida com a mãe, que servirá como modelo para as relações estabelecidas posteriormente. Em confluência com o autor, Cintra e Ribeiro (2018, p. 120) ressaltam que a prevalência do movimento projetivo de aspectos bons favorece a introjeção do bom objeto e, consequentemente, a integração, enquanto o protagonismo da projeção das partes más do self geraria a intensificação da angústia persecutória em relação ao objeto.

Posteriormente, Wilfred Bion $(1961 / 1991 ; 1962 / 1988)$ desenvolve o conceito ao sublinhar a vertente comunicacional da identificação projetiva. Klein já havia comentado, a respeito da dimensão "normal" desse processo psíquico, como vital e determinante para as relações objetais amorosas e para os processos de integração do ego (KLEIN, 1946/2006, p. 27-28); no entanto, coube a Bion (1961/1991) enfatizar o caráter comunicativo da identificação projetiva e assinalar a sua importância para o interjogo emocional que ocorre na dupla mãe-bebê. Grotstein (2007/2010) explica que a identificação projetiva para Melanie Klein engloba o modelo de apenas uma pessoa, que tem como seu componente a fantasia intrapsíquica onipotente, de ordem inconsciente.

Na obra de Bion, o modelo de duas pessoas é central, pois leva em consideração as respostas do objeto à identificação projetiva e as modificações da função continente. Grotstein (2007/2010) comenta que, para Klein, a prevalência da dimensão evacuatória, agressiva e possessiva era característica da identificação projetiva, enquanto Bion compreendia que o bebê estava comunicando suas emoções ao objeto, na expectativa que esse contivesse e mediasse suas angústias. Grotstein (2007/2010) ainda ressalta que a versão de Bion a respeito da modalidade comunicativa bimodal da identificação projetiva inclui a dimensão intrapsiquíca kleiniana e 
acrescenta o eixo intersubjetivo, evidenciando o papel do objeto na dinâmica da identificação projetiva, que modifica ativamente a experiência que o sujeito vivencia (GROTSTEIN, 2007/2010).

Nesse sentido, para apreendermos a diferença essencial entre as concepções de Bion e de Klein a respeito da identificação projetiva, é necessário que compreendamos o modelo de aparelho psíquico que o primeiro propõe, em especial em seu texto A teoria do pensar (1961/1991). Conforme sublinha Chuster et al. (2014), o texto supracitado constitui um dos três principais momentos da obra de Bion, ao lado da teorização a respeito dos grupos e da proposta de um modelo espectral, composto de infinitas possibilidades entre partes psicóticas e não-psicóticas da personalidade. Nessa obra, Bion postula um modelo do psiquismo baseado na importância da tolerância à frustração para o desenvolvimento da capacidade de pensar/sonhar no bebê, quando acolhida pelo processo de rêverie materna (1961/1991).

Bion propõe uma importante descrição do desenvolvimento dos pensamentos, utilizando termos como preconcepções, concepções (pensamentos) e conceitos. Para o autor, a pressão exercida pelos pensamentos provoca o surgimento da capacidade pensar. Seguindo esse raciocínio, Bion expõe que a concepção é resultante da conjunção inicial entre uma preconcepção e uma realização. O modelo ao qual recorre o autor é o do bebê que possui uma expectativa de um seio; "quando o bebê é posto em contato com o próprio seio, associa-se com a consciência da realização e é sincrônica ao desenvolvimento de uma concepção" (BION, 1961/1991, p. 186). Chuster et al. definem a preconcepção como "[...] uma expectativa vaga de que, no futuro, exista um objeto onipotente e psiquicamente acolhedor capaz de preencher as necessidades e incompletudes humanas" (2014, p. 66). Também acrescentam que o pensamento em Bion surge a partir da introjeção de um objeto no qual a realização precisa lidar simultaneamente com a frustração e a satisfação. Dessa forma, o pensamento pressupõe a existência de um processo de integração, que coincide com o conceito de posição depressiva (CHUSTER et al., 1999, p. 97).

A capacidade do bebê de tolerar a frustração será crucial para que tal experiência se transforme em um pensamento e o aparelho de pensar pensamentos se desenvolva de forma satisfatória. "Se a frustação pode ser tolerada, a associação de concepção e realizações, sejam negativas ou positivas, dá início a procedimentos necessários para aprender com a experiência" (BION, 1961/1991, p. 188). Nesse sentido, destacamos a importância atribuída por Bion ao ajuste necessário entre a mãe e seu bebê, onde a identificação projetiva ocupa um lugar central. "[...] o bebê é capaz, através da operação de um senso de realidade rudimentar, de comportar-se de tal modo que a identificação projetiva - normalmente uma fantasia onipotente - funcione como um fenômeno realista" (BION, 1961/1991, p. 188). Diferentemente da dimensão excessiva descrita originalmente por Melanie Klein (1946/2006), o autor descreve que tal atividade realista seria própria a essa forma rudimentar de comunicação e que "visa despertar na mãe sentimentos dos quais o bebê deseja livrar-se" (BION, 1961/1991, p. 189). Uma vez que o bebê não consegue dar conta por si só desses elementos em estado bruto, ele os evacua para dentro da mãe, na esperança que esta os transforme em elementos alfa que o bebê possa sonhar. "A capacidade da mãe de rêverie é o órgão receptor da colheita de sensações que o bebê, através de seu consciente, obtém do self" (BION, 1961/1991, p. 190).

Quando a rêverie materna é incapaz de conter os elementos brutos projetados pelo bebê, a identificação projetiva assume uma dimensão patológica de pura descarga, que prescinde da dimensão de comunicação sublinhada anteriormente. $O$ bebê é forçado a reintrojetar os sentimentos intoleráveis de volta para si, internalizado como um terror inominável. (BION, 1961/1991, p. 190). O grau de frustração se torna intolerável para o psiquismo do bebê, que é invadido por objetos bizarros impossíveis de serem metabolizados, cujo único recurso para descarga seria a utilização da identificação projetiva como um mecanismo de evacuação. Em função do grau intolerável de frustração que assola o psiquismo, o ódio assume um papel protagonista na relação primordial mãe-bebê, uma vez que o bebê se sentiria assolado por objetos aterrorizantes, que adquirem tal conotação em função da falha da rêverie materna em acolhê-los de forma harmônica. Portanto, a prevalência do ódio busca mitigar a existência do próprio aparelho psíquico e de sua capacidade de pensar, assim como os vínculos entre objetos internos e externos, uma vez que a função integrativa da rêverie encontra-se abalada, assim como a identificação projetiva é utilizada de forma evacuativa (BION, 1957/1991).

É importante salientar a ênfase que Bion atribui ao sonhar para a construção do modelo relacional mãe-bebê, assim como a importante dinâmica emocional que se estabelece entre a mente da mãe, que, conforme descrevemos anteriormente, funciona como uma espécie de aparelho digestivo para o psiquismo do bebê. Nesse sentido, conceitos como rêverie materna, função alfa e continente-contido assumem grande importância para a compreensão da constituição psíquica, uma vez que descrevem a forma pela qual a mãe acolhe elementos indigestos do seu bebê e os devolve qualitativamente transformados, passíveis de serem sonhados por ele. Descrevemos anteriormente a importância da capacidade de sonhar da mãe para a constituição psíquica do bebê, denominada por Bion como rêverie materna. Posteriormente, Bion amplia o modelo do sonhar quando 
propõe o conceito de função alfa, descrita pelo autor como a função responsável por prover material para os pensamentos oníricos através da conversão de dados sensoriais em elementos alfa, "[...] e, portanto, a capacidade para acordar ou dormir, para estar consciente ou inconsciente" (BION, 1961/1991, p. 189). Assim, a capacidade de rêverie materna é descrita como um dos componentes da função alfa, responsável pela metabolização dos elementos sensoriais em oníricos e que está presente na globalidade das relações interpessoais.

O conceito de função alfa é determinante para o modelo de aparelho psíquico elaborado por Bion, pois reafirma a importância do sonhar para a constituição do aparelho psíquico. Nessa direção, Bion refina sua teorização a respeito das propriedades da função alfa, descrevendo os elementos alfa e beta. $O$ primeiro seriam elementos passíveis de serem sonhados pela mente do bebê, uma vez que são apreendidos de forma satisfatória pela mente materna. Por sua vez, os elementos beta constituem impressões sensoriais brutas, ainda não metabolizadas pela função alfa (BION, 1962/1991). Assim como no modelo da rêverie materna, tais elementos brutos buscam ser transformados em elementos sonháveis. Quando os elementos beta não encontram uma mente capaz de metabolizá-los, tais elementos psíquicos adquirem uma tonalidade bizarra própria à parte psicótica da personalidade, que adota a identificação projetiva como forma de evacuação ao invés de canal de comunicação, como forma desesperada de lidar com o grau excessivo de frustração.

A prevalência desses elementos bizarros no psiquismo compromete o processo de comunicação da identificação projetiva, que passa a funcionar de forma defensiva, como forma de evacuação. Em função do grau elevado de frustração, ocasionado pela impossibilidade do funcionamento da rêverie materna, a constituição do psiquismo encontra-se ameaçada por objetos internos aterrorizantes, que impedem a capacidade de fazer vínculos e de simbolizar. A incidência dessas falhas em momentos precoces da constituição subjetiva afeta diretamente a zona arcaica do aparelho psíquico, responsável pelos processos de simbolização primária e pelos primeiros movimentos de integração. Desse modo, prosseguiremos com a investigação das repercussões dessas falhas precoces na subjetividade, em especial quando incidem na parte bebê do self (CICCONE, 2011; 2012; 2013), prejudicando os processos de simbolização primária (ROUSSILLON, 2012).

\section{A PARTE BEBÊ DO SELF E A DIMENSÃO SENSORIAL PRIMITIVA}

Albert Ciccone (2013) nomeia como a parte bebê do self a zona mais arcaica do psiquismo, responsável pelos processos de simbolização primária e, consequentemente, os primeiros processos de integração do aparelho psíquico. Nesse sentido, as falhas que incidem nessa área da subjetividade, advindas dos impasses da relação mãe-bebê e da incapacidade da rêverie materna de acolher as angústias primárias do bebê (BION 1961/1991; 1962/1991) desencadeiam graves modalidades psicopatológicas, conforme assinalamos anteriormente. Exploraremos a seguir algumas ideias do autor supracitado e de outros, tais como Frances Tustin (1980; 1981; 1984) e Donald Winnicott (1956/2000; 1965/2018) no intuito de aprofundar nossa investigação a respeito das vicissitudes das falhas relacionais ocorridas em períodos precoces da constituição psíquica.

Ciccone (2013) propõe que pensemos a parte bebê do self a partir de uma noção ampliada do conceito de infantil em Freud. Inspirado pela investigação inaugurada por Melanie Klein (1952/1985) a respeito da vida psíquica do bebê e suas relações primordiais objetais, o autor expõe que é essencial que consideremos as experiências precoces não só da infância, mas também aquelas concernentes à vivência do bebê que habita o interior do sujeito. Esse aspecto é importante para o desenvolvimento teórico do autor, uma vez que considera que os sofrimentos psíquicos mais intoleráveis e desorganizadores estão localizados na parte bebê do self que coabita o adulto.

É importante salientar a ideia que o autor traz a respeito da temporalidade própria a essa zona arcaica do psiquismo. Para Ciccone (2013), é importante que pensemos o infantil, que englobaria também os aspectos precoces da dinâmica psíquica, como um núcleo que participa ativamente das interações do sujeito no aqui-e-agora, em contraste com um entendimento atrelado apenas a considerar os aspectos do passado e seus efeitos no presente a partir do après-coup. A parte bebê permanece vívida, tanto no modo como interpreta as experiências do mundo como também na forma que se protege do sofrimento. Portanto, além da dimensão histórica, o aspecto bebê da personalidade também se manifesta de forma ativa e presente na situação analítica, uma vez que é compreendida de forma dinâmica e atual ao invés de estática, vinculada apenas a uma etapa do desenvolvimento psíquico (CICCONE, 2013).

O autor destaca duas formas de experiência emocional próprias à manifestação da parte bebê: as experiências de dependência, vulnerabilidade e desamparo em um polo; e as experiências de ilusão de onipotência, no outro polo, como forma de defesa frente ao sofrimento do primeiro polo. Ciccone (2013) destaca que a onipotência é um efeito do inchaço narcísico que busca o estancamento da dor causada por uma angústia infantil; essa manifestação narcísica, por sua vez, pode se desdobrar em aspectos destrutivos e tirânicos no desenvolvimento. Nesse sentido, o cuidado psíquico a ser oferecido na situação analítica se dá na competência em distinguir entre 
esses dois polos de sofrimento da parte bebê e, posteriormente, buscar contato e reparação com a parte bebê em sofrimento. É importante ressaltar que a reparação a qual o autor faz menção é proposta por Melanie Klein como um dos processos psíquicos relativos à posição depressiva, que entraria em ação quando o bebê sente que seus impulsos sádicos teriam danificado o objeto. A culpa ocupa um lugar central nessa dinâmica, pois induz o bebê a se preocupar com o objeto, um aspecto determinante para a capacidade de amar, de acordo com a autora (KLEIN, 1929/1996). Quando a angústia depressiva assume um caráter dominante, a reparação adquire um caráter maníaco, que tenta negar a dependência do sujeito em relação ao objeto ao construir uma fantasia de onipotência (KLEIN, 1940/1996).

Como último aspecto a ser exposto do pensamento de Albert Ciccone, veremos de que forma o autor propõe o entendimento da parentalidade cuidadora, na qual se apoiam os primeiros cuidados proferidos ao bebê, assim como suas experiências primitivas com o ambiente e com o objeto. Tal modelo possui grande relevância para o manejo clínico de sofrimentos psíquicos arcaicos, em especial aos referentes à parte bebê do psiquismo, uma vez que são determinantes para a formação do mesmo. O casal parental, a partir das suas funções paterna e materna, participa ativamente da constituição psíquica do bebê através de suas próprias experiências pessoais arcaicas, que trazem marcas singulares próprias a cada sujeito. Desse modo, cabe aos primeiros cuidadores o cuidado e a metabolização das angústias arcaicas do bebê para que haja o desenvolvimento dos processos de integração e de simbolização.

A partir das contribuições de Donald Winnicott (1956/2003; 1965/2018) a respeito da preocupação materna primária, Ciccone (2013) propõe o conceito de preocupação parental primária. O autor inglês descreve um estado psíquico particular da mãe, em seus últimos momentos de gravidez e algumas semanas após o nascimento do bebê, no qual ela mergulha em uma sensibilidade aguçada em relação ao bebê e suas necessidades vitais. Esse processo, comparado por Winnicott a um estado de dissociação ou esquizoidia (FAIRBAIRN, 1940), permite que o bebê se aproprie das primeiras sensações dessa fase da vida, ao propiciar um ambiente suficientemente bom que se devota aos cuidados do infans (WINNICOTT, 1956/2003). Essa devoção inicial da mãe em relação ao seu bebê é essencial para que haja uma primeira organização do ego, que é construído de forma silenciosa e harmônica quando a função materna acolhe as necessidades corporais do bebê e não interrompe o desenvolvimento do going-on-being (WINNICOTT, 1956/2003). Ciccone (2013) propõe uma ampliação da perspectiva de Winnicott ao discorrer que a preocupação primária não seria prioritariamente materna ou paterna, pois necessita da conjugação das qualidades de ambas as funções, assim como o estado de maior sensibilidade e atenção à vida emocional do outro e a dimensão arcaica do mesmo também permeia ambos cuidadores (CICCONE, 2013).

A articulação dos elementos maternos e paternos constitui, à medida que o bebê recebe ativamente os cuidados do casal parental, a bissexualidade psíquica. Ciccone (2013) destaca a importância da forma primária da bissexualidade, a bissensualidade psíquica, inspirado nas contribuições de Frances Tustin $(1980 ; 1981 ; 1984)$ a respeito das formas arcaicas que permeiam a autossensualidade do psiquismo. Nesse âmbito, é importante frisar a relação entre os opostos sensuais, referentes às sensações primárias experimentadas pelo bebê, em especial aquelas ligadas à experiência sensorial do que seria mole e duro. Para Tustin (1984), as formas permeiam o mundo psíquico do bebê através da sensação das fezes, do contato da comida com os lábios e do seio com a boca, que, ao proporcionar repetitivas experiências, delineiam contornos que determinam suas associações com os objetos (TUSTIN, 1984). Tais formas primordiais estão ligadas diretamente aos processos de diferenciação entre a mãe e seu bebê, através do qual este estabelece certas conexões mentais com ela enquanto objeto externo. Tustin ainda relaciona a experiência do bebê com essas formas precoces com a possibilidade de relação com o mundo externo, assim como sua importância para o funcionamento emocional, estético e cognitivo (TUSTIN, 1984).

A experiência com essas formas primárias ou objetos-sensação (TUSTIN, 1980) ocorre em um momento em que o bebê ainda não possui discernimento entre o seu próprio corpo e o mundo externo, no qual há o predomínio da dimensão sensorial, assim como a ênfase na autorreferência. Como ainda não há uma distinção clara entre a boca do bebê e o seio da mãe, assim como as fronteiras entre o eu e o outro, tais objetos-sensação portam uma dimensão autística, que protegem o psiquismo em formação dos momentos em que o bebê percebe a diferença que há entre ele e sua mãe. Tustin diz que os objetos-sensação autísticos são dotados de uma dureza específica, que auxilia o bebê a sentir segurança frente à iminência da angústia de separação. Para apaziguar, é utilizado o desconforto proveniente dessa ameaça frente ao não-eu, proporcionando uma satisfação sensual que mantém o estado de não percepção em relação aos limites que separam o bebê de sua mãe (TUSTIN, 1980).

A partir das contribuições de Tustin a respeito do papel dos objetos-sensação na formação do psiquismo, em especial em sua dimensão corporal, Ciccone (2013) discorre que o tônus corporal seria o lugar onde acontece a integração dos aspectos mais arcaicos das funções maternas e paternas e nas quais se entrelaçam as experi- 
ências corporais precoces. $\mathrm{O}$ tônus adquire as qualidades de rigidez paterna e de suavidade materna. $\mathrm{O}$ bebê internaliza uma "coluna vertebral" paterna, que lhe dá segurança frente à experiência com o mundo externo, ao mesmo tempo em que também se apropria do envelope materno, que permite que ele se adapte e se ajuste nesse encontro com o mundo. Tais elaborações estão em confluência com as contribuições de Frances Tustin a respeito das experiências precoces com os objetos-sensação, que se expressam na relação auto sensual do bebê com o seu próprio corpo e permitem que sobreviva aos impactos precipitados com o mundo externo (TUSTIN, 1980). A matriz dura permite que o bebê adquira a confiança corporal para aceder aos processos de integração mais refinados, ao mesmo tempo que a matriz mole conserva a maleabilidade necessária para lidar com as contingências do mundo externo (CICCONE, 2013).

Nesse sentido, Ciccone (2013) propõe que o cuidado psíquico direcionado à parte bebê do self pressupõe que o cuidador tenha mantido guardado o contato com os aspectos adultos e infantis - experiências infantis concernentes tanto ao desamparo e dor como aos movimentos narcísicos de onipotência. Tal experiência é indispensável para compreender o sofrimento da parte bebê dos pacientes, assim como ajudá-los a reparar os movimentos narcísicos onde a onipotência se apresenta como pseudomaturidade (MELTZER, 2008/2017). Quando falhas severas se instauram na parte bebê do self, em função do uso patológico da identificação projetiva e da impossibilidade da rêverie materna em assimilar os conteúdos brutos, é possível inferir que o ódio prevalece enquanto vínculo na dinâmica relacional frente à intensidade de frustração vivenciada como desorganizadora. O polo onipotente prevalece no funcionamento do self, apresentando uma robustez narcísica que se manifesta na clínica através de atuações drásticas que evidenciam a precariedade dos processos de integração das sensações primitivas que permeiam os primórdios da vida psíquica. O fragmento clínico a seguir ilustra a nossa argumentação.

Rafael chega extremamente perturbado ao meu consultório. Cabelos desarrumados, esbaforido, olheiras profundas que quase camuflam seus olhos desorientados, que imploram por atenção. Na sessão anterior, havia se recusado em se deitar no divã, pois dizia que precisava me ver, olhar diretamente pra mim. Ou melhor, que alguém olhasse para ele. Diz que está desesperado, pois perdeu todas as referências que possuía em sua vida.

Ao entrar em meu consultório, senta-se na poltrona em frente à minha e começa a falar alto, esbravejando que não conseguiu escolher nada em sua vida, que todos os caminhos lhe foram ditados por pessoas ou instituições. Começa a urrar, se bater severamente nas pernas e nos peitos. Aguardo em silêncio. Ele continua, em uma espécie de choro sem lágrimas crescente, urrando cada vez mais alto, ao mesmo tempo em que desfere socos em suas pernas e tapas em seu peito. Passam-se vários minutos nessa situação, em que observo cuidadosamente as suas reações e emoções.

Em determinado momento, ele se aninha na poltrona, com as duas pernas contraídas contra o peito, alisando seus longos cabelos em uma espécie de gesto auto-calmante. Narro para ele que, tal qual um bebê, ele havia chorado, gritado e esperneado na esperança de que alguém viesse resolver todos os seus problemas, mas, uma vez que isso não aconteceu, ele precisava arranjar outras formas de encarar o sofrimento. Na sequência, Rafael coloca um dos dedos em sua boca e experimenta um estado de completo relaxamento na poltrona; dou continuidade à minha intervenção, comunicando a ele que agora experimentava um estado de relaxamento que não consegue encontrar em nenhum outro lugar a não ser em meu consultório, sob o meu olhar, e que é preciso que criemos uma nova forma de encarar as desventuras do mundo adulto, do qual ele tanto reclama. Encerramos a sessão em silêncio.

\section{CONSIDERAÇÕES FINAIS}

No presente trabalho, buscamos uma maior compreensão a respeito dos primórdios da vida psíquica, em especial nos casos em que há falha da rêverie materna na relação mãe-bebê. Nesse sentido, exploramos as contribuições de Melanie Klein e Wilfred Bion a respeito da identificação projetiva, compreendida como forma rudimentar e básica de comunicação, assim como a importância da qualidade desse primeiro encontro. Vimos também os impactos ocorridos quando o continente materno não consegue acolher o material bruto do bebê, que, nesses casos, se depara com elementos intraduzíveis, que provocam terrores inomináveis e marcam profundamente áreas arcaicas do psiquismo do bebê.

Posteriormente, seguimos com a descrição da zona arcaica da subjetividade, caracterizada por Albert Ciccone como a parte bebê do self. Para o autor, essa área do psiquismo é responsável pelos primeiros processos de simbolização e integração, sendo assim determinante para a formação do psiquismo e da relação entre o bebê e seu objeto primordial. Percorremos as contribuições de Frances Tustin a respeito das primeiras sensações do bebê em relação ao seu corpo e de que forma são determinantes para a dinâmica objetal. As sensações de mole e de duro, descritas pela autora como opostos sensuais, funcionam como matrizes estruturantes do aparelho psíquico do bebê. 
Por fim, trouxemos um fragmento clínico com o intuito de ilustrar nossa investigação. A dificuldade do manejo clínico ao lidar com falhas tão precoces, que, por sua vez, desencadeiam formas extremas de defesa, apresenta-se no material clínico em questão através do apelo à dimensão corporal/sensorial, uma vez que o trabalho de simbolização foi inviabilizado pelos traumatismos precoces.

Recebido em: 11 de maio de 2020. Aprovado em: 20 de dezembro de 2021.

\section{REFERÊNCIAS}

BION, W. R. Ataques ao elo de ligação (1957). In: BOTT SPILLIUS, E. (org.). Melanie Klein: desenvolvimentos da teoria e da técnica, v.1. Rio de Janeiro: Imago, 1991.

BION, W. R. Learning from experience (1962). London: Karnac, 1991.

BION, W. R. Uma teoria do pensar (1961). In: BOTT SPILLIUS, E. (org.). Melanie Klein: Desenvolvimentos da teoria e da técnica, v.1. Rio de Janeiro: Imago, 1991.

BOTT SPILLIUS, E. et al. The new dictionary of kleinian thought. London: Routledge, 2011.

CHUSTER et al. Novas leituras: dos modelos científicos aos princípios ético-estéticos, 1 - parte teórica. Rio de Janeiro: Companhia de Freud, 1999.

CHUSTER et al. W. R Bion: a obra complexa. Porto Alegre: Sulina, 2014.

CICCONE, A. La part bébé du soi et les formes primaires de la subjectivité. In: BRUN, A.; ROUSSILLON, R. (orgs.). Formes primaires de symbolisation. Paris: Dunod, 2013.

CICCONE, A. La psychanalyse à l'épreuve du bébé. Paris: Dunod, 2011.

CICCONE, A. (org.). La part bébé du soi: approche clinique. Paris: Dunod, 2012.

CINTRA. E.; RIBEIRO, M. Por que Klein? São Paulo: Zagodoni, 2018.

FAIRBAIRN, R. Factores esquizoides na personalidade. In: FAIRBAIRN, R. Estudos psicanalíticos da personalidade. Lisboa: Editorial Vega, 1940.

FREUD, S. Tres ensayos de teoria sexual (1905). Buenos Aires: Amorrortu, 2010. (Obras completas de Sigmund Freud, 7)

GROTSTEIN, J. Um facho de intensa escuridão: o legado de Wilfred Bion à psicanálise (2007). Porto Alegre: Artmed, 2010.

KLEIN, M. Notas sobre alguns mecanismos esquizoides (1946). In: KLEIN, M. Inveja e gratidão e outros trabalhos (1946-1963). Rio de Janeiro: Imago, 2006.

KLEIN, M. O luto e suas relações com os estados maníaco-depressivos (1940). In: KLEIN, M. Amor, culpa e reparação e outros trabalhos (1921-1945). Rio de Janeiro: Imago, 1996.

KLEIN, M. Situação de ansiedade infantil refletidas em uma obra de arte e no impulso criativo (1929). In: KLEIN, M. Amor, culpa e reparação e outros trabalhos (1921-1945). Rio de Janeiro: Imago, 1996.

KLEIN, M. Sobre a observação do comportamento de bebês (1952). In: KLEIN, M. Inveja e gratidão e outros trabalhos (1946-1963). Rio de Janeiro: Imago, 2006.

MELTZER, D. O Claustro: uma investigação dos fenômenos claustrofóbicos (2008). São Paulo: Blucher, 2017.

MELTZER, D. O desenvolvimento kleiniano III: o significado clínico da obra de Bion. São Paulo: Escuta, 1998.

OGDEN, T. H. This Art of Psychoanalysis: dreaming undreamt dreams and interrupted cries. New York: Routledge, 2005.

PETOT, J-M. Melanie Klein II: o ego e o bom objeto (1979). São Paulo: Perspectiva, 2016.

TUSTIN, F. Autistic objects. International Review of Psycho-Analysis, n. 7 (1), p. 27-40, 1980, Londres: Routledge.

TUSTIN, F. Autistic shapes. International Review of Psycho-Analysis, n. 11, p. 279-290, 1984. Londres: Routledge.

TUSTIN, F. Estados autísticos em crianças (1981). Rio de Janeiro: Imago, 1984.

ROUSSILLON, R. Agonie, clivage et symbolisation. Paris: Press Universitaires de France, 2012.

WINNICOTT, D. W. Primary maternal preoccupation (1956). In: WINNICOTT, D. W. Through Paediatrics to Psycho-analysis: collected papers. Londres: Routledge, 2003.

WINNICOTT, D. W. The maturational processes and the facilitating environment (1965). Londres, Routledge, 2018.

\section{Daniel Pinho Senos de Jesus}

danielsenos@gmail.com

Silvia Maria Abu-Jamra Zornig

silvia.zornig@gmail.com 